\title{
O Uso de Recursos Florestais e as Políticas Econômicas Brasileiras - Uma Visão Histórica e Parcial de um Processo de Desenvolvimento
}

Carlos José Caetano Bacha

Professor da ESALQ/USP

\section{RESUMO}

Este artigo analisa o uso de recursos florestais no Brasil, evidenciando que a destruição de nossas florestas e o uso insustentável dos remanescentes florestais sempre se associaram com as políticas desenvolvimentistas adotadas no País. Estas políticas, por sua vez, se fundamentaram nos principais modelos econômicos em voga a cada período. $O$ trabalho apresenta uma discussão acerca da importância das florestas para uma nação e ressalta que o Brasil as está destruindo em grande escala, enquanto diversos outros países as ampliam. Este processo de desmatamento no Brasil já não se justifica pela necessidade de terra para a produção agropecuária. Por meio de um instrumental analítico, o trabalho verifica as políticas florestais e seus resultados desde o Brasil colônia e as associam com os principais modelos existentes a cada período. O trabalho também analisa o processo de reflorestamento no Brasil, demonstrando que o mesmo não compensa a perda de florestas nativas. Ao seu final, o artigo discute algumas políticas que permitem o uso racional dos recursos florestais no Brasil sem impedir a expansão de outras atividades econômicas.

\section{PALAVRAS-CHAVE}

florestas, destruição, políticas, modelos econômicos

ABSTRACT

This paper analyzes the use of forests in Brazil, pointing out the destruction of native forests and its unsustainable uses are due to development policies. The latter is connected with the main economic models that prevailed during each time period. The paper discusses about the importance of forests for a nation and it points out Brazil is world's number one in losing forests, while other countries are increasing their forests. That deforestation is not necessary in order to keep Brazil's agriculture growing. The paper makes an analysis of forest policies and their results along Brazil's history. The paper also analyzed the reforestation in Brazil and shows it is not compensating the deforestation process. At the end, the paper suggests some policies that are able to keep the expansion of agriculture and to conserve native forests in Brazil.

KEY WORDS

forests, depletion, policies, economic models

JEL Classification

Q01, Q23, O13 


\section{INTRODUÇÃO}

O objetivo deste artigo é analisar o uso de recursos florestais no Brasil, evidenciando como este uso se associa com as políticas econômicas adotadas para estimular o desenvolvimento econômico do País.

As causas imediatas do desmatamento são a expansão da agropecuária, a criação de infra-estrutura econômica (como estradas, hidrelétricas, barragens, por exemplo), a expansão urbana e a extração florestal. Há diversos autores que alegam que essas causas primárias do desmatamento são estimuladas por políticas desenvolvimentistas (ver, por exemplo, GILLIS \& REPETTO, 1988; MAHAR, 1989; BROWDER, 1992). No entanto, não há um trabalho que associe essas políticas desenvolvimentistas com os principais modelos econômicos existentes para fins de formulação de políticas econômicas. O presente trabalho faz essa associação, tomando em consideração o uso de recursos florestais no Brasil.

A hipótese deste trabalho é que a destruição dos recursos florestais no Brasil e o uso insustentável dos remanescentes florestais sempre estiveram associados com as políticas desenvolvimentistas adotadas no País, as quais, por sua vez, se fundamentaram nos principais modelos econômicos em voga a cada período.

Esta exposição compõe-se de sete seçôes, incluindo esta introdução. A seção a seguir discute a importância das florestas para uma economia, o que justifica a permanência de uma certa cobertura florestal. A seção 2 analisa a dimensão e evolução do desmatamento no Brasil, ressaltando sua evolução diferenciada entre as regiões brasileiras. A seção 3 apresenta uma análise histórica do uso de recursos florestais no País, evidenciando como a destruição das matas nativas esteve associada com o estilo de desenvolvimento adotado pelo País, o qual, por sua vez, se amparava nas principais formulaçóes econômicas em discussão. A seção 4 analisa o esforço de reflorestamento feito no Brasil, associando este com o estilo de desenvolvimento adotado pelo País e os efeitos que o reflorestamento teve para compensar tal processo de desmatamento. A título de conclusão, discutem-se algumas políticas que podem ser adotadas de modo a conter o processo de desmatamento do País e permitir o uso de recursos florestais de maneira sustentável. 


\section{A IMPORTÂNCIA DAS FLORESTAS EM UMA NAÇÃO}

As florestas podem ser utilizadas de modo a produzir benefícios ecológicos nem sempre comercializáveis, como fonte de ecoturismo e para produzir produtos de base florestal.

De acordo com Viana (2002, p. 101), "As florestas produzem diferentes serviços ambientais, dentre os quais destacam-se: o seqüestro de carbono para atemuar mudanças do clima, proteção de mananciais de água para abastecimento, conservação de margens de hidrovias, conservação da biodiversidade, fornecimento de polinizadores e inimigos naturais de pragas e doenças para cultivos agricolas, entre outros." Dentre esses outros tem-se, por exemplo, a proteção de espécies farmacológicas. (CAMINO,1999, p. 101).

Esses serviços ambientais fornecidos pelas florestas não têm sido cobrados; mas se isto for possível, a receita oriunda das florestas aumentaria substancialmente. O próprio Camino (1999, p. 101-102) afirma que: "os proprietários de florestas privadas no México estão perdendo um minimo de US\$ 4 bilhões, a cada ano, de componentes não comercializáveis do valor total das florestas ... Estimativas do valor econômico total das florestas da Costa Rica ... mostram que os proprietários destas florestas (inchindo as do estado) falham em receber aproximadamente $82 \%$ do valor total das florestas (incluindo as áreas protegidas), e 72\% do valor por hectare das florestas produtivas ... ."

O ecoturismo leva os viajantes a florestas tropicais, a locais de flora e fauna preservados, a praias paradisíacas e a outros lugares de vegetação intacta. Este tipo de turismo tem se mostrado economicamente viável em diversos casos. Em 1992, ele representou 7\% do turismo internacional. Além disso, ele ajuda a conservar as florestas naturais. (DOUROJEANNI, 1999, p. 90). Avaliação recente indica que o ecoturismo movimenta US\$ 238 bilhões no mundo. (Isto É, 2002, p. 96).

Os produtos comercializáveis de base florestal são divididos em dois grupos: a) madeira e produtos baseados na madeira; b) produtos não madeireiros. (SIMULA, 1999, p. 197). O primeiro grupo inclui: 
1. Produtos primários, tais como a lenha, o carvão vegetal, a madeira em tora e os cavacos;

2. Produtos oriundos da primeira transformação industrial da madeira, tais como a madeira serrada, os painéis a base de madeira, a celulose e o papel;

3. Os produtos florestais mais elaborados e com maior valor adicionado, tais como: produtos de madeira usados na construção civil (portas, janelas, assoalhos, entre outros), móveis de madeira.

Os produtos florestais não madeireiros "abrangem uma grande série de itens desde as plantas medicinais e aromáticas até nozes, frutas, resinas, tanino, ceras e produtos de artesanato." (SIMULA, 1999, p. 200).

A importância, acima mencionada, das florestas tem feito com que diversos países evitem perdê-las ou as recuperem. Segundo o relatório COFO (2001), o Japão e o Canadá não alteraram as dimensões de suas coberturas florestais (nativa e plantada) entre 1990 e 2000, as quais cobriam 26,5\% do território canadense e $66 \%$ do território japonês. Os países europeus aumentaram suas florestas (nativas e plantadas) em 8,7 milhões de ha entre 1990 e 2000, e os EUA as elevaram em 3,9 milhões de ha. Em 2000, as florestas cobriam $45,7 \%$ do território europeu e $24,7 \%$ do território norteamericano.

No entanto, o Brasil seguiu o caminho inverso. Este país foi o maior destruidor de florestas entre 1990 e 2000 , perdendo 22 milhões de hectares. O segundo colocado neste rank, a Indonésia, perdeu 13 milhões de hectares.

Poder-se-ia pensar que o Brasil tem uma cobertura florestal acima da média dos demais países, o que explicaria esta perda de recursos florestais. De fato, o Brasil tinha, em 2000, 62,3\% de seu território coberto com florestas. (COFO, 2001). No entanto, elevada porcentagem de cobertura florestal também é encontrada em diversos outros países em que não se observa perda de cobertura florestal. Em 2000, 72\% da superfície da Finlândia era coberta com florestas. Esta porcentagem era de $66,8 \%$ na Suécia e $66 \%$ no 
Japão. Até mesmo países menos desenvolvidos do que o Brasil mantêm elevada cobertura florestal em seu território, como a Guiana Francesa (90\%) e o Suriname $(86,4 \%)$, por exemplo.

De outro lado, poder-se-ia alegar que as florestas não têm importância econômica para o Brasil. Isto também não é correto. Os produtos de madeira e os da primeira transformação industrial da madeira representaram $8,7 \%$ das exportações brasileiras em 1999 e foram responsáveis, direta e indiretamente, por 1,8 milhão de empregos. (BACHA, 2001).

Do exposto acima, pode-se inferir que as florestas não são usadas no Brasil de modo a maximizar os benefícios, econômicos e ambientais, que podem ser obtidos a partir delas.

De modo a entender esse processo, é importante uma análise histórica de como o desmatamento tem ocorrido no Brasil.

\section{A EVOLUÇÃO DO DESMATAMENTO NO BRASIL}

É fato notório que o Brasil tem destruído os seus recursos florestais durante todo o seu processo de desenvolvimento econômico e não apenas em período recente. Apesar das atenções serem, atualmente, centradas no desmatamento que ocorre na Amazônia Legal, este processo atingiu proporções maiores em outras regiões, onde os benefícios ecológicos das florestas foram em grande parte perdidos.

Desde o seu descobrimento pelos portugueses, em 1500, as florestas naturais brasileiras têm sido removidas com o intuito de dar lugar a outras atividades agropecuárias, industriais (inclusive mineração), de infra-estrutura econômica (como estradas e hidrelétricas, por exemplo) ou para expansão urbana. Segundo a Fundação SOS Mata Atlântica (1998), em 1912 os Estados das regiões Sul e Sudeste detinham cobertura florestal de aproximadamente $^{1}$ 48,9 e 33,9 milhões ha, respectivamente. Em 1995, as

1 Os dados de São Paulo se referem a 1907 e do Rio Grande do Sul a 1940. Os demais Estados possuem área com cobertura florestal estimada no ano de 1912. 
coberturas florestais dessas regióes eram de, respectivamente, 4,4 e 4,2 milhões ha. ${ }^{2}$ Em 83 anos, as regiões mais desenvolvidas do Brasil perderam 74,2 milhões de ha. A partir de meados da década de 70, o desmatamento intensificou-se na Amazônia Legal. Entre 1975 e 1999, essa região perdeu 44,9 milhões de hectares (INPE, 2000), o que corresponde a pouco menos do que duas vezes o território do Reino Unido.

Essa perda de recursos florestais poderia ser considerada normal em um país que desenvolve suas atividades agropecuárias, industriais e urbanas. No entanto, a intensidade deste processo, o modo como ele vem sendo feito e a falta de garantia de que os remanescentes florestais serão utilizados de maneira sustentável (ou que não serão extintos no futuro) contrastam com a importância que a presença de florestas tem para uma economia.

O processo de desmatamento tem intensidade diferente entre os Estados brasileiros. As Tabelas 1, 2 e 3 trazem as porcentagens das áreas dos estados brasileiros que eram cobertas com florestas ou com vegetação nativa em anos selecionados.

TABELA I - PORCENTAGEM DA ÁREA TERRITORIAL COBERTA COM FORMAÇÃO FLORESTAL - ESTADOS DAS REGIOEES SUDESTE E SUL (VALORES EM PORCENTAGEM)

\begin{tabular}{lccc}
\hline Estado & Situação em 1500 & Situação em 1985 & Situação em 1995 \\
\hline Minas Gerais & 51,70 & 2,30 & 2,02 \\
Espírito Santo & 86,88 & 10,01 & 8,90 \\
Rio de Janeiro & 97,00 & 27,14 & 21,07 \\
São Paulo & 81,80 & 8,22 & 7,64 \\
Paraná & 84,72 & 10,12 & 8,93 \\
Santa Catarina & 81,50 & 19,14 & 17,41 \\
Rio Grande do Sul & 39,70 & 3,06 & 2,69 \\
\hline
\end{tabular}

Fonte: Fundação SOS Mata Atlântica (1998).

2 A Fundação SOS Mata Atlântica reviu os dados de 1995, elevando-os (ver FUNDAÇÃO MATA ATLÂNTICA, 2002). No presente trabalho prefere-se ainda trabalhar com os dados divulgados no trabalho de 1998, pois eles são consistentes com as séries históricas anteriores a 1995 . 
TABELA 2 - PORCENTAGEM DA ÁREA TERRITORIAL COBERTA COM FORMAÇÃO FLORESTAL - ESTADOS QUE COMPÓEM A AMAZÔNIA LEGAL (VALORES EM PORCENTAGEM)

\begin{tabular}{lccc}
\hline Estado & Situação em 1500 & Situação em 1975 & Situação em 1999 \\
\hline Acre & 98,90 & 98,10 & 89,05 \\
Amazonas & 97,94 & 97,89 & 96,05 \\
Roraima & 76,85 & 76,82 & 74,13 \\
Rondônia & 95,93 & 95,42 & 72,74 \\
Pará & 92,77 & 89,52 & 77,16 \\
Amapá & 85,45 & 85,34 & 84,07 \\
Tocantins & 99,46 & 98,16 & 89,60 \\
Maranhão & 90,64 & 66,17 & 51,32 \\
Mato Grosso & 97,73 & 96,58 & 80,58
\end{tabular}

Fonte: INPE (2000).

TABELA 3 - PORCENTAGEM DA ÁREA TERRITORIAL COBERTA COM VEGETAÇÃO NATIVA (FLORESTAS, CERRADO, CAATINGA, CAMPO, PANTANAL) - ESTADOS QUE COMPÖEM O NORDESTE E CENTRO-OESTE (VALORES EM PORCENTAGENS)

\begin{tabular}{lccc}
\hline Estado & \multicolumn{3}{c}{ Situação em 1500 Situação na década de $70^{\mathrm{a}}$ S Situação na década de 80} \\
\hline Piauí & 93,13 & 90,68 & $56,57^{\mathrm{b}}$ \\
Ceará & 93,46 & 73,24 & $15,66^{\mathrm{b}}$ \\
Rio Grande do Norte & 97,01 & 69,44 & $43,46^{\mathrm{b}}$ \\
Paraíba & 98,98 & 53,55 & $30,00^{\mathrm{b}}$ \\
Pernambuco & 96,30 & 58,27 & $49,41^{\mathrm{b}}$ \\
Sergipe & 96,86 & - & $37,60^{\mathrm{b}}$ \\
Alagoas & 98,69 & - & $22,80^{\mathrm{b}}$ \\
Bahia & 95,29 & 64,53 & $48,08^{\mathrm{b}}$ \\
Goiás & - & - & $27,10^{\mathrm{c}}$ \\
Mato Grosso do Sul & 97,23 & - & $44,89^{\mathrm{d}}$ \\
\hline
\end{tabular}

Fonte: BACHA (1995), o qual coletou dados de diversas publicaçôes.

Notas: a) Para o Piauí e a Paraíba essa informação se refere aos anos de 1971 a 1973. Para os demais Estados, dizem respeito aos anos de 1977 a 1981; b) refere-se ao biênio $1988 / 89$; c) refere-se ao ano de 1983 ; d) refere-se ao ano de 1982. 
Os resultados dessas tabelas permitem constatar o seguinte:

a) Os Estados das regiões Sudeste e Sul foram os que mais perderam cobertura florestal, havendo casos onde esta cobertura está abaixo do nível mínimo aconselhado por órgãos internacionais. O Programa das Nações Unidas para o Meio Ambiente, PNUMA, sugere que no mínimo 10\% do território de uma região deve ser preservado com vegetação nativa. Isto não inclui o que deve ser mantido para exploração florestal sustentável. Nas regiốes Sudeste e Sul, apenas os Estados do Rio de Janeiro e Santa Catarina atendem, atualmente, a esse mínimo de cobertura florestal natural.

b) Os Estados do Nordeste tiveram grande alteração da cobertura vegetal entre as décadas de 70 e 80 . Este fato tem sido pouco relatado na literatura.

c) Os Estados que compóem a Amazônia Legal ainda possuem grandes coberturas florestais. No entanto, o desmatamento tem sido intenso em alguns desses Estados, os quais têm perdido rapidamente sua cobertura florestal. Maranhão, Mato Grosso, Pará e Rondônia (onde há forte expansão da agropecuária) são responsáveis por $86 \%$ do desmatamento que ocorre nessa região, apesar de responderem por $52 \%$ da área da região. Este processo de desmatamento é o que mais chama a atenção da comunidade científica internacional, pois se repete na Amazônia Legal o mesmo processo de destruição das florestas que ocorreu na Mata Atlântica. (VIANA, 2002, p. 4).

d) Os dados agregados de desmatamento em nível de Estado não evidenciam a desigualdade que este fenômeno pode ter dentro de cada Estado. Por exemplo, na Amazônia Legal, "muitos municípios já possuem mais de $50 \%$ de desmatamento e alguns já se encontram em niveis semelhantes aos da Mata Atlántica.” (VIANA, 2002, p. 1).

O processo de desmatamento tem sido feito de forma desordenada. A riqueza florestal existente foi, na maioria das vezes, apenas queimada, sem que a madeira pudesse ser aproveitada e destruindo-se ecossistemas que não podem mais ser recuperados integralmente. A abundância de terras no País, associada com a expansão do sistema de transporte, fez com que a necessidade de ampliar a produção agropecuária fosse atendida por novas áreas para plantio, ao invés de se melhorar a exploração de terras já desmatadas. 
Considerando as 38 principais culturas ${ }^{3}$ existentes no Brasil, constata-se que a área cultivada passou de 54,2 milhões de hectares em 1989 para 49,2 milhões de hectares em 2001. Simultaneamente, a produção aumentou de 377 milhões de toneladas em 1989 para 503 milhões de toneladas em 2001, implicando o fato de a produtividade da terra passar de 6.953 ton/ha para 10.219 ton/ha, respectivamente. Esses dados foram extraídos do Anuário Estatístico do Brasil.

Como conseqüência do acima mencionado, grandes áreas ociosas já desmatadas e aptas à produção agropecuária existem dentro dos estabelecimentos agrícolas. Por exemplo, nos Estados que compõem a região da Amazônia Legal havia, em 1995, 6,89 milhões de hectares dentro dos estabelecimentos agropecuários que eram considerados como "Área produtiva não utilizada”. Apenas essas áreas ociosas permitiriam ampliar em $80 \%$ a área atual ocupada com lavouras nesta região sem a necessidade de novos desmatamentos.

Outro fenômeno associado ao desmatamento e à expansão agropecuária é a grande quantidade de áreas degradadas e, hoje, sem aproveitamento agropecuário. Segundo Viana (2002, p. 96), há 20 milhões de hectares de áreas degradadas, as quais, após o desmatamento, foram aproveitadas de maneira inapropriada para fins agropecuários.

Não bastasse o processo de desmatamento, os remanescentes florestais são utilizados de maneira insustentável. Apesar de haver práticas de manejo sustentável já aprovadas tecnicamente, ${ }^{4}$ a maioria das explorações madeireiras ainda se faz com técnicas insustentáveis. Isto porque estas últimas envolvem maior lucro a curto prazo, apesar de inviabilizar a exploração florestal no futuro. Os dados da Tabela 4 evidenciam que a exploração clandestina de toras de madeiras e o seu processamento são mais lucrativos do que a exploração autorizada e não sustentável. Esta última é, por sua vez, mais lucrativa do que a exploração autorizada e sustentável das florestas nativas.

3 Essas culturas são: abacate, algodão-arbóreo, algodão-herbáceo, alho, amendoim, arroz, aveia, batata, cacau, café, cana, castanha, cebola, centeio, cevada, coco, feijão, fumo, goiaba, guaraná, juta, laranja, limão, maçã, malva, mamona, mandioca, manga, maracujá, milho, pimenta, sisal, soja, sorgo, tangerina, tomate, trigo e uva.

4 Ver a proposta de CARTERPILLAR ( 1996). 


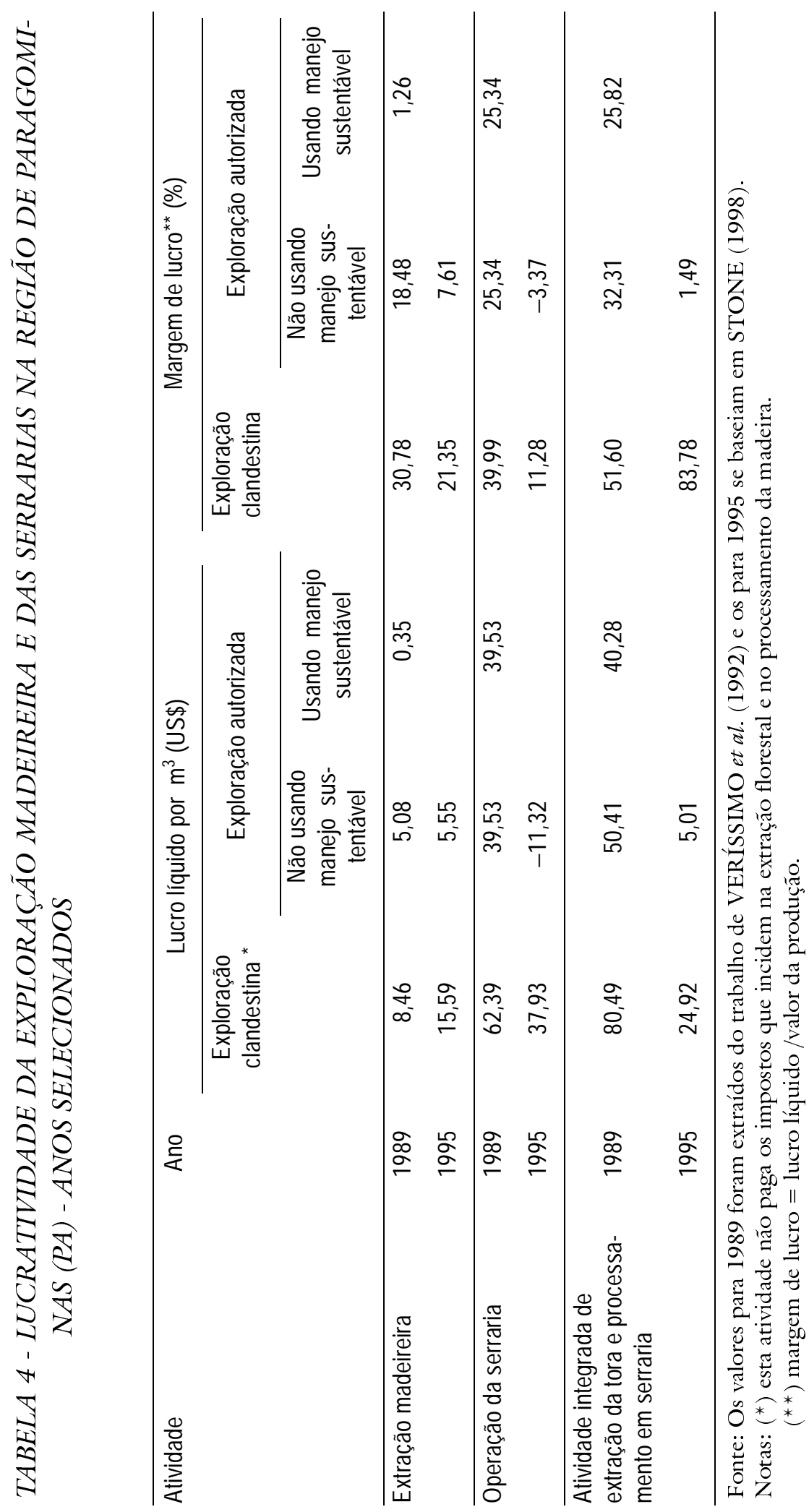

Est. econ., São Paulo, 34(2): 393-426, abr-jun 2004 


\section{VISÃO HISTÓRICA DO USO DE RECURSOS FLORESTAIS NO BRASIL}

A análise do uso de recursos florestais e das políticas referentes a esses recursos é feita em três grandes períodos da história do Brasil: o período colonial, o período imperial e o período do Brasil República. No entanto, maior atenção é dada ao período que começa na década de 1960.

Procura-se evidenciar que o País adotou políticas desenvolvimentistas que implicavam destruição dos recursos florestais. Estas políticas eram, no entanto, compatíveis com as principais formulações econômicas em vigência a cada época, as quais, por sua vez, não consideravam os recursos florestais como um elemento essencial nos modelos econômicos. À medida que a destruição dos recursos florestais pudesse afetar o desenvolvimento econômico do País, os governos trataram de estabelecer políticas de comando e controle, as quais, em princípio, deveriam disciplinar o processo de desmatamento.

\subsection{O Uso de Recursos Florestais no Brasil Colonial}

Quando do descobrimento do Brasil pelos portugueses, em 1500, predominava no pensamento econômico as idéias mercantilistas. Estas atribuíam ao estoque de metais preciosos o parâmetro para medir a riqueza das nações e, por causa disso, políticas econômicas que levassem ao aumento dos estoques desses metais eram sugeridas. (HUGON, 1973, p. 61-93). Uma dessas políticas era a dos países europeus estabelecerem colônias em outras terras e garantir o monopólio das transações econômicas da colônia com a metrópole. Assim, os países centrais poderiam obter produtos a preços baixos e negociá-los com outros países detentores de metais preciosos. Outra vantagem do sistema colonial era garantir o direito de explorar os recursos minerais encontrados na colônia. Essas políticas foram seguidas pelos portugueses durante o período em que o Brasil foi colônia de Portugal.

Durante os dois primeiros séculos de soberania portuguesa, os metais preciosos não foram encontrados em expressiva escala no Brasil. No entanto, de imediato as árvores de pau-brasil foram exploradas, pois delas se obtinha a produção de tinta vermelha, muito utilizada na Europa dos séculos XVI e XVII para o tingimento de roupas.

Est. econ., São Paulo, 34(2): 393-426, abr-jun 2004 
A coroa portuguesa se incumbiu de estabelecer regras para garantir o monopólio da exploração da madeira do pau-brasil. Assim, apenas os agentes autorizados pelo rei de Portugal ou pelo seu representante podiam abater árvores de pau-brasil.

Durante todo o período colonial, a exploração dos recursos florestais no Brasil foi conduzida de maneira insustentável. O ritmo de desmatamento foi mais intenso em certas áreas do País onde se desenvolvia intensamente a agropecuária, como, por exemplo, na área litorânea do Nordeste nos séculos XVI e XVII, na qual se desenvolvia a lavoura de cana-de-açúcar, e no interior nordestino, no qual se desenvolvia a pecuária. No século XVIII, estas atividades tiveram período de declínio, mas as matas nativas não foram repostas. No último quartel do século XVIII, o Maranhão presenciou um "boom" de plantio de algodão, que era exportado para a Inglaterra. (FURTADO, 1989).

Diante desse cenário, a Coroa portuguesa apenas adotou algumas medidas de comando e controle do desmatamento ${ }^{5}$ que, em princípio, poderiam amenizar os efeitos negativos do processo de desmatamento sobre o crescimento da economia e que garantiriam a sua soberania sobre as riquezas florestais do País (ver CASTRO, 1975; ZANIOLO, 1988; e AZEREDO, 1988).

\subsection{O Uso de Recursos Florestais no Brasil Imperial}

O período imperial foi marcado pela grande expansão cafeeira nos Estados de Rio de Janeiro, São Paulo e Minas Gerais. Segundo dados apresentados por Albuquerque e Nicol (1987, p. 167), as exportações brasileiras de café aumentaram da média anual de 317,8 mil sacas no período de 1821 a 1830 para 5.332,6 mil sacas anuais no período de 1881/90. Isto só foi possível graças ao grande crescimento da produção nacional de café, que ocorreu com o desmatamento de parte dos Estados supracitados.

5 Tais como: (1) proibições de cortes em certas áreas ou de determinadas espécies arbóreas, (2) limites quantitativos na exploração de florestas e (3) monopólio português sobre algumas riquezas florestais. 
Além da expansão da lavoura cafeeira, existiram outros sistemas agropecuários, os quais também contribuíram para o desmatamento. Entre estes sistemas destacam-se: a lavoura canavieira no litoral do Nordeste, a pecuária extensiva no interior do Nordeste, as lavouras de algodão no Maranhão e Ceará, as lavouras de cana-de-açúcar em São Paulo e a pequena agricultura baseada em colonos estrangeiros no Sul do País. Apenas essa última foi iniciada no período imperial, sendo que as demais tiveram origem no período colonial. O único sistema extrativista de destaque era a exploração de cacau e borracha na Amazônia. (FURTADO, 1989). No entanto, nenhum desses sistemas agropecuários teve a mesma importância econômica que a expansão cafeeira.

A expansão dos cafezais se fez acompanhada de forte desmatamento. Entre 1854 e 1886 houve o desmatamento de 2,3 milhões de hectares no Estado de São Paulo, com média anual de 71.875 hectares. (SOS MATA ATLÂNTICA, 1998, p. 37). Nesses 32 anos, 0,3\% do território paulista foi desmatado anualmente.

Durante o período imperial, as idéias econômicas dos economistas clássicos e, posteriomente, dos economistas neoclássicos prevaleceram no pensamento econômico. No entanto, os autores clássicos pouco se dedicaram a analisar o papel das florestas na economia. Considerando a teoria do valor trabalho - que indica que o valor de uma mercadoria depende da quantidade de trabalho humano necessário a produzi-la - poder-se-ia concluir que a floresta nativa em pé não teria valor, pois não foi necessário trabalho humano para gerá-la. Assim, o desmatamento seguido do plantio da área com uma nova cultura ou a extração não sustentável de madeiras não estaria incoerente com o pensamento clássico vigente, pois neste caso há a incorporação de trabalho para se gerar um novo produto.

Os neoclássicos do século XIX também colocaram os recursos naturais como uma variável secundária em suas análises. Segundo Buarque (1983), para os neoclássicos o sistema de preços e o progresso técnico conduzem a uma oferta adequada de recursos naturais. Se ocorrer a redução da oferta de um recurso natural, haverá o aumento do seu preço. Isto conduz ao aumento da oferta de tal recurso. Se, no entanto, a escassez do recurso natural for 
muito intensa e sua perda for irreversível, a elevação do preço desse produto conduzirá ao uso de substitutos ou ao desenvolvimento deles (aqui considerando a inovação tecnológica).

Tanto os autores clássicos como os neoclássicos defendiam, no século XIX, a liberdade de mercado na condução das atividades econômicas. Dentro dessa linha, os governos imperiais intervieram pouco na economia, em especial no processo de desmatamento seguido do plantio da área com uma nova cultura. Continuou-se com as políticas florestais de comando e controle que vinham sendo adotadas desde o período colonial, buscando agora garantir o monopólio da exploração das matas nativas para o Império e estabelecer penalidades para a destruição não autorizada de florestas (ver BACHA, 1993, p. 70).

\subsection{O Uso de Recursos Florestais no Brasil Republicano}

Para efeito de exposição, pode-se dividir o período a partir de 1889 em quatro fases, as quais presenciaram políticas florestais com diferentes intensidades. Essas fases são: o período da república velha (1889 a 1929), o período de 1930 a 1964, o período de 1965 a 1988, e o período pós 1988.

\subsubsection{Periodo de 1889 a 1929}

Neste período houve o domínio das idéias neoclássicas na formulação de políticas econômicas. Como já ressaltado no item 3.2, esses autores não atribuíam, em sua primeira fase, um papel expressivo aos recursos naturais. Isto explica, em parte, o fato de nas três primeiras décadas de período republicano (1889 a 1920) nenhuma política florestal de maior significância ter sido adotada, apesar de ocorrer a intensificação do processamento de desmatamento, em conseqüência da expansão das atividades agropecuárias, urbanas e de infra-estrutura (principalmente a construção de ferrovias). No Estado de São Paulo foram desmatados 6,4 milhões de hectares entre 1886 e 1920, com média anual de 188.971 ha, ou seja, 0,76\% da superfície estadual por ano (FUNDAÇÃO SOS MATA ATLÂNTICA, 1998, p. 37), sendo que a maior parte do material florestal foi apenas queimada. 
O estilo de construção adotado no Brasil, fruto da herança portuguesa, privilegiava o uso de pedras, tijolos e areia. A madeira era pouco utilizada na construção habitacional. Além disso, a falta de conhecimento sobre as espécies florestais brasileiras levou ao uso de madeira importada. Segundo Zenid (1997, p. 16) "A despeito da disponibilidade de grandes reservas florestais e do inicio da produção de madeira serrada de pinho, as duas primeiras décadas deste século" (século XX) "foram marcadas pela importação significativa de madeiras serradas e beneficiadas, do hemisfério norte, para atender à demanda das cidades do Rio de Janeiro e São Paulo.”

Uma medida isolada foi a criação, em 28/12/1921 (por meio do Decreto $\mathrm{n}^{\mathrm{o}}$ 4.421 ), do Serviço Florestal do Brasil, órgão que era vinculado ao Ministério da Agricultura. Nessa época começou-se a discutir a criação de unidades de conservação de modo a preservar alguns ecossistemas em áreas que sofriam rápido processo de desmatamento.

\subsubsection{O Periodo de 1930 a 1964}

A década de 30 presenciou o primeiro conjunto amplo de medidas destinadas a proteger os recursos naturais do Brasil. A crise econômica mundial, associada ao ceticismo em relação às principais idéias econômicas dos economistas neoclássicos, permitiu ao governo autoritário de Getúlio Vargas elaborar diversos códigos de proteção dos recursos naturais, como: o Código Florestal (Decreto n⿳⼈ㅡ 23.793 de 23/01/34), o Código das Águas (Decreto n⿳⺈ 24.643 de 10/07/34), e o Código da Pesca (Decreto-lei nº 794 de 1938).

A idéia desses códigos era estabelecer limites no uso de recursos naturais, os quais estariam de acordo com o discutido na teoria sobre as externalidades (como o livro de $\mathrm{PIGOU}^{6}$ ) e com as formulações teóricas a respeito do limite de uso de recursos naturais (como o modelo de HOTTELING ${ }^{7}$ de 1931).

6 A. C. PIGOU. The economics of welfare. London: Macmillan, 1932.

7 H. HOTELLING. The economics of exhaustible resources. In: Joumal of Political Economy, Chicago, 39, p. 137-175, Abril de 1931. 
O Código Florestal de 1934 adotou os seguintes instrumentos de comando e controle do desmatamento:

- Limites ao uso da terra dentro da propriedade rural. Esta deveria ser dividida em três áreas: as áreas livres para exploração, as áreas de reserva legal (no mínimo, $25 \%$ da propriedade rural) e as florestas ao redor de cursos d’água (as matas ciliares).

- A obrigatoriedade do proprietário rural pedir a autorização prévia do governo federal para explorar as áreas com matas nativas próximas de rios e lagos navegados ou de estradas de ferro.

- A obrigatoriedade de grandes consumidores de produtos florestais (como empresas siderúrgicas e as de transporte) de manter o cultivo de florestas para suprimento de lenha ou carvão vegetal. Isto implicava a reposição florestal por parte dessas empresas.

- A criação de unidades de conservação visando proteger certos ecossistemas em áreas em fase rápida de desmatamento. Entre essas unidades de conservação estavam as florestas de rendimento (futuras florestas nacionais), os parques e as florestas protetoras. Estas últimas serviam para conservar o regime das águas; evitar a erosão das terras pela ação dos agentes naturais; fixar dunas; auxiliar a defesa das fronteiras; assegurar condições de salubridade pública; proteger sítios com beleza natural; asilar espécies raras da fauna indígena.

O Instituto Nacional do Pinho (INP) foi o órgão encarregado de fazer cumprir os instrumentos de comando e controle do desmatamento presentes no Io Código Florestal. Posteriormente, o INP foi substituído nesta função pelo Departamento de Recursos Naturais Renováveis do Ministério da Agricultura.

Não obstante sua amplitude, os mecanismos criados pelo Código Florestal de 1934 foram pouco implementados. A razão para isto pode ser encontrada no tipo de desenvolvimento adotado pelo País. Este privilegiou o desenvolvimento de atividades industriais e urbanas, as quais implicavam certo desmatamento. Para financiar essas atividades, o Estado adotou política 
cambial e fiscal que transferia parte da renda da agropecuária para as atividades industriais. Manter a agropecuária expandindo era, dentro desta política desenvolvimentista, um elemento importante. Isto explica por que o governo federal não alocou recursos para cumprir o que estava estabelecido no Código Florestal de 1934.

É importante ressaltar que nas décadas de 40,50 e 60 o principal modelo macroeconômico orientando as formulações de políticas macroeconômicas era a teoria keynesiana (hoje incorporada na Síntese Neoclássica). Essa divide a economia em cinco mercados (mercado de produtos, moeda, título, trabalho e divisas), e não dá atenção ao papel dos recursos naturais dentro da economia.

A equação de equilíbrio no mercado de produto é:

$$
\mathrm{Y}=\mathrm{C}+\mathrm{I}+\mathrm{G}+\mathrm{X}-\mathrm{M}
$$

onde Y é o PIB, C é o consumo do setor privado, I é o investimento do setor privado, G são os gastos do governo, X são as exportações e M são as importações.

Tomando em consideração apenas o mercado de produto, pode-se imaginar que seria uma política desenvolvimentista coerente com este modelo as seguintes situações:

- Novos investimentos (aumento de I) com o objetivo de converter áreas cobertas com florestas em áreas agrícolas,

- Aumento de gastos do governo (aumento de G) visando criar novas estradas e hidrelétricas (que geravam o desmatamento),

- As empresas explorando as florestas de maneira insustentável e obtendo mais produtos que aumentassem as exportações (aumento de $\mathrm{X}$ ) ou diminuíssem as importações (diminuição de $\mathrm{M}$ ).

Estas medidas de fato aconteceram. Os dados dos censos agropecuários indicam que entre 1940 e 1970 foram criados 3 milhões de estabelecimentos 
agropecuários, e a área total dos estabelecimentos agropecuários ampliou-se em 100 milhões de hectares.

O estilo de crescimento da produção agropecuária contribuiu significativamente para o desmatamento do Brasil. Entre 1940 e 1970, a expansão agropecuária deveu-se, basicamente, à expansão de área cultivada. Goldin e Rezende (1993, p. 15-16) - baseados no trabalho de Melo $^{8}$ (1987) - afirmam que os acréscimos de áreas cultivadas foram responsáveis por $72 \%$ do crescimento da produção agrícola nos anos 50 e por $65 \%$ nos anos 60 .

Entre 1938 e 1964 houve o aumento de 356 mil km de estradas de rodagem (ou seja, acréscimo ${ }^{9}$ de $185 \%$ ), devido aos investimentos feitos pelo governo neste tipo de infra-estrutura.

A exploração predatória dos pinheirais da região Sul permitiu ao País gerar divisas com a exportação deste tipo de madeira.

\subsubsection{Periodo de 1965 a 1988}

Este período presenciou uma nova fase de recrudescimento de medidas de comando e controle do desmatamento, sem criar estímulos econômicos à preservação de florestas nativas.

Em 15/09/65 foi promulgada a Lei 4.771, conhecida como 2ํㅡㅁódigo Florestal. Esse último procurou ser mais minucioso do que o Código Florestal de 1934. As principais adiçôes e modificações podem ser vistas no Quadro 1. Destacam-se: a) a ampliação das áreas de preservação permanente; b) a diferenciação da dimensão da reserva legal de acordo com a localização da propriedade; c) a obrigatoriedade de autorização do Poder Público para explorar todas as florestas nativas; d) a obrigatoriedade de planos de manejo para explorar as florestas do Nordeste, Norte e Centro-Oeste; e) a obrigatoriedade de reposição florestal por todos os consumidores de produtos florestais.

8 MELO, F. H. Export-orientated agricultural growth: the case of Brazil. Genebra: September 1987 (World Employment Programme Research Working Paper).

9 De acordo com o Anuário Estatístico do Brasil, em 31/12/1938 havia $192.612 \mathrm{~km}$ de estradas de rodagem no Brasil e em 31/12/1964 havia $548.510 \mathrm{~km}$. 


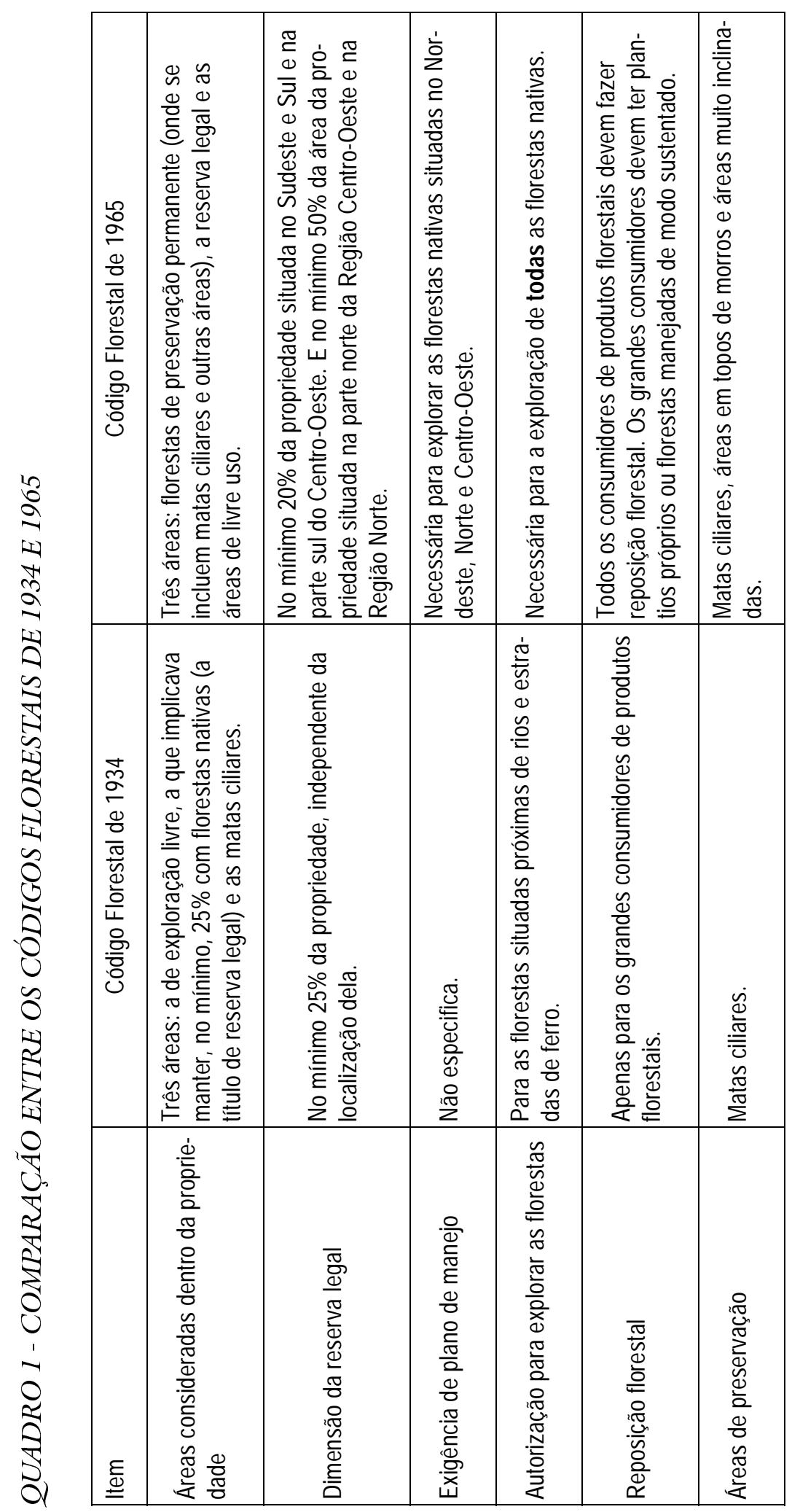

Est. econ., São Paulo, 34(2): 393-426, abr-jun 2004 
A execução da política florestal passou a ser competência do Instituto Brasileiro de Desenvolvimento Florestal (IBDF), criado em 28/02/67 e que incorporou o Instituto Nacional do Pinho e sucedeu o Departamento de Recursos Naturais Renováveis dentro do Ministério da Agricultura.

Apesar de sua maior rigorosidade, as medidas de comando e controle foram pouco aplicadas. Essas medidas não condiziam com outras adotadas pelo governo federal, tais como:

- Estímulos econômicos (via crédito rural e política de garantia de preços) para a expansão da produção agropecuária na década de 70 e na primeira metade da década de 80 . Isto explica o avanço da agropecuária em direção ao Centro-Oeste, o qual, necessariamente, implicou aceleração do desmatamento nesta região.

- Os governos (federal, estaduais e municipais) ampliaram a malha rodoviária de 548 mil km em 1964 para 1.502 mil km em 1988, o que permitiu o acesso a áreas antes isoladas.

- O governo federal dava incentivos econômicos para projetos agropecuários na Amazônia e no Nordeste (por meio da SUDAM e SUDENE), projetos esses que implicavam desmatamentos.

- Diversos conflitos surgiram entre a legislação florestal e outras legislações federais. Por exemplo, o estatuto da terra garantia a posse da terra àquele que lhe fizesse benfeitoria. Uma dessas benfeitorias era a limpeza da área, ou seja, o seu desmatamento.

Na primeira metade da década de 70 , as críticas formuladas à teoria anteriormente dominante (a teoria keynesiana) se concentraram na falta de fundamentos microeconômicos nas construções macroeconômicas e na ausência de expectativas racionais. Os modelos novo-clássicos e novo-keynesianos surgiram para superar essas deficiências, mas eles não deram aos recursos naturais significativa relevância, o mesmo acontecendo no Modelo da Síntese Neoclássica. ${ }^{10}$ Os recursos naturais foram incluídos como geradores de

10 A Síntese Neoclássica incorporou parte das críticas dos Novos-clássicos às construções da Teoria Keynesiana. 
choques de oferta (como, por exemplo, um aumento exógeno do preço do petróleo), os quais explicaram a estagflação enfrentada pelos países desenvolvidos em alguns anos da década de 1970. (BLANCHARD, 2001, p. 154-159).

Neste período em análise (década de 70 e começo da década de 80) observam-se, no mínimo, duas tentativas para incorporar os recursos naturais em modelos macroeconômicos. A primeira diz respeito a introduzir os recursos naturais no modelo neoclássico de crescimento. Stiglitz (1974) alega que esse modelo não encontra equilíbrio, enquanto Cigno (1981) prova que o equilíbrio existe. A segunda se refere à proposta de Sachs (1990) de utilizar a equação de crescimento proposta por Michael Kalechi de maneira a mostrar como a utilização racional dos recursos naturais pode levar ao crescimento do produto. No entanto, nenhum desses dois modelos propostos foi considerado como sendo fundamental para elaborar políticas econômicas.

\subsubsection{O Periodo Pós 1988}

Em outubro de 1988 foi promulgada a Nova Constituição brasileira, a qual garantiu aos Estados o direito de legislar, de maneira competitiva com a União, a respeito dos recursos florestais. Isto deu condições para os Estados criarem suas legislações florestais. Estas, de modo similar à legislação federal, reforçaram as medidas de comando e controle do desmatamento.

No entanto, um novo instrumento foi criado para incentivar os municípios a preservarem áreas protetoras de mananciais de água ou unidades de conservação. Trata-se do ICMS Ecológico. Este último implica alocar parcela do ICMS arrecadado aos municípios que têm que preservar áreas florestais que protegem os recursos de uso em comum. Trata-se de uma compensação a esses municípios pelos benefícios ecológicos que suas florestas geram para a população vizinha.

O ICMS Ecológico iniciou-se no Estado do Paraná em 1992, tendo sido adotado $^{11}$ por São Paulo (em 1994), Minas Gerais (em 1996), Rondônia

11 Os anos mencionados neste parágrafo referem-se aos de implementação do ICMS Ecológico. As leis que os criaram antecedem aos anos de implementação. 
(em 1997), Rio Grande do Sul (em 1999) e Mato Grosso do Sul (em 2002), além de outros Estados estarem discutindo sua adoção. (BACHA \& SHIKIDA, 1999). Os resultados deste instrumento não são extraordinários, mas são positivos no sentido de preservar as matas nativas dentro e fora das unidades de conservação.

Apesar dessa criatividade em nível estadual, o governo federal manteve sua política de comando e controle do desmatamento, ampliando as medidas anteriormente estabelecidas, de modo a torná-las mais eficazes.

Cinco grandes conjuntos de medidas foram tomados após 1988, quais sejam:

- Definição de uma política global para o meio ambiente, com o reconhecimento de que os recursos naturais se interagem. Assim, em 1989 foi criado o Instituto Brasileiro do Meio Ambiente e dos Recursos Naturais Renováveis (IBAMA), que assumiu as responsabilidades e patrimônios de órgãos que fiscalizavam recursos específicos, como o Instituto Brasileiro de Desenvolvimento Florestal (IBDF), a Superintendência da Borracha (SUDHEVEA), a Superintendência da Pesca (SUDEPE) e a Secretaria Especial do Meio Ambiente (SEMA).

- Instituição da obrigatoriedade de Relatório de Impacto Ambiental (RIMA) em projetos que afetassem o meio ambiente, como construção de estradas, hidrelétricas, mineração e grandes projetos agropecuários.

- Aperfeiçoamento da legislação florestal, criando a obrigatoriedade de reposição, dentro dos estabelecimentos agropecuários, das áreas de preservação de nascentes de rios (Lei 7.754 de 14/04/89) e da Reserva Legal (Lei 8.171 de 17/01/1991 e Medida Provisória 2166), e a criação de Lei de Crimes Ambientais (Lei 9.605 de 12/02/1998), que introduz maior clareza na individualização da responsabilidade criminal. Esta lei foi sancionada 8 anos após sua primeira tramitação no Congresso e regulamentada apenas em 2000 . 
- Cancelamento de incentivos fiscais para projetos agropecuários que levassem ao desmatamento da Amazônia Legal.

- Ampliação da reserva legal. Essa última passou, a partir de 2000, a valer para todos os tipos de vegetação nativa, tendo a dimensão de $80 \%$ nos imóveis rurais situados em áreas de cobertura florestal na Amazônia Legal (reduzindo-se esse limite a 50\% caso o imóvel rural esteja em áreas sujeitas ao Zoneamento ecológico-econômico), 35\% em áreas cobertas com cerrado na Amazônia Legal e 20\% nos demais imóveis rurais do Brasil (cobertos com cerrado, campo, floresta ou caatinga).

A ênfase nessas medidas de comando e controle do desmatamento, enfocando a disciplina do desmatamento em termos de unidades produtivas, não evitou o desmatamento no Brasil. O que mais chamou a atenção da comunidade, nacional e internacional, foram os 19,18 milhões de hectares de florestas destruídos na Amazônia Legal entre 1988 e 1999. No entanto, não menos importante são, também, os 1,13 milhão de hectares de florestas perdidas nas regiões Sul e Sudeste entre 1985 e 1995, pois os Estados dessas regiões têm baixa cobertura florestal.

Mas, por que um país com uma legislação pormenorizada para controlar o desmatamento, como o Brasil, não atinge esse objetivo?

Basicamente, porque esse objetivo não condiz com as outras políticas desenvolvimentistas. Na década de 90, o Brasil adotou medidas condizentes com o chamado Consenso de Washington (políticas de caráter neoliberal). Estas buscam: a) disciplina fiscal, redirecionando as prioridades de gastos públicos para as áreas de saúde, educação e infra-estrutura; b) reforma fiscal, visando ampliar a base fiscal e reduzir impostos marginais; c) definir a taxa de câmbio em termos competitivos; d) garantir direitos à propriedade; e) desregulamentar a economia; f) reduzir a participação do Estado no processo produtivo por meio da privatização de empresas estatais; g) liberalização comercial e dos fluxos de capitais. (BAUMANN, 2000, p.13). Essas reformas deveriam ser feitas de forma gradual, sendo as dos itens $e$ e $g$ classificadas como de primeira geração e as demais de segunda geração. 
A necessidade de controlar o déficit público e também de ampliar as exportações levaram ao enfraquecimento dos órgãos públicos que realizam a fiscalização da destruição dos recursos naturais, como o caso das florestas. Isto explica o avanço do desmatamento na Amazônia Legal, onde áreas cobertas com florestas são convertidas em pastagens e plantações de soja, e cujas produções se orientam, em parte, para o setor externo. Nos Estados da Amazônia Legal, os órgãos ambientais não adquirem o mesmo status que os órgãos vinculados com a produção.

Os recursos naturais, como as florestas nativas, ainda não assumiram um papel importante nos modelos macroeconômicos, apesar desses recursos serem parte importante de uma série de outros modelos econômicos.

Os modelos macroeconômicos em voga no período pós 1988 continuaram sendo os Monetaristas, os Novo-clássicos e os Novos-keynesianos, agora dando maior atenção às questôes de equilíbrio no longo prazo, desemprego (como o modelo Insider-Outsider), rigidez nominal de preços (como o Menu Cost), rigidez de salários reais (Modelos de Salário Eficiência e de Contrato de Trabalho) e os modelos de crescimento econômico (Modelo do Ciclo Econômico Real). Novamente os recursos naturais não são considerados nesses modelos. (DORNBUSCH \& FISCHER, 1991, p. 783-824; e BLANCHARD, 2001, p. 598-607).

No entanto, paralelamente a esses modelos macroeconômicos, dinamizou-se uma ampla literatura sobre desenvolvimento sustentável e sustentabilidade (ver ROCHA, 1999, p. 16-24). Esta literatura não apresenta consenso sobre o modo de obter o desenvolvimento sustentável, mas teve o impacto de aumentar a preocupação dos formuladores de políticas econômicas quanto à sustentabilidade do processo de desenvolvimento econômico.

Esforços têm ocorrido para alterar a metodologia de cálculo dos agregados econômicos de modo a calcular a renda sustentável. Esta última se obtém ao descontar das medidas convencionais da renda a depreciação dos recursos naturais e do meio ambiente. Daly (1992), Harrison (1992) e El Serafy (1992) propõem diferentes metodologias para calcular a renda sustentável. Alguns trabalhos foram realizados para o Brasil considerando setores especí- 
ficos (tais como os trabalhos de MOTTA \& YOUNG, 1991, e o de BASTOS FILHO, 1995) e evidenciando que a renda sustentável é inferior à obtida pelo Sistema de Contas Nacionais tradicional. Não obstante, os valores calculados pelo SCN tradicional ainda são os mais utilizados para efeito de avaliação das economias.

\section{O REFLORESTAMENTO NO BRASIL}

O Brasil tinha, em 2000, a sexta maior área reflorestada no Mundo, a qual era apenas inferior às encontradas na China, Índia, Federação Russa, Estados Unidos e Japão. (COFO, 2001, p. 31-34). Neste ano, havia um estoque de 4,98 milhões de hectares plantados com florestas no Brasil.

O plantio de florestas no Brasil teve grande dinamismo no período de 1965 a 1986, no qual foram concedidos incentivos fiscais para o reflorestamento, os quais se inseriam em ampla política de incentivos fiscais para desenvolvimento setorial e regional. O estoque de área reflorestada passou de cerca de 1,66 milhão de hectares em 1970 para 5,97 milhões em 1985 (Tabela 5). No entanto, este estoque diminuiu para 5,4 milhões de ha em 1995 e para 4,98 milhões de hectares em 2000. A falta de novos incentivos e o longo prazo de maturação do investimento realizado explicam a redução do ritmo de reflorestamento no Brasil, apesar desta ser uma atividade lucrativa.

TABELA 5 - ESTOQUE DE FLORESTAS PLANTADAS NO BRASIL

\begin{tabular}{lccccc}
\hline & $31 / 12 / 70$ & $31 / 12 / 75$ & $31 / 12 / 80$ & $31 / 12 / 85$ & $31 / 12 / 95^{*}$ \\
\hline Area plantada com florestas (ha) & 1.658 .225 & 2.864 .298 & 5.015 .713 & 5.966 .012 & 5.396 .016 \\
Número de árvores reflorestadas (mil) & 2.585 .984 & 5.371 .340 & 9.227 .460 & 9.690 .493 & 7.065 .381 \\
\hline
\end{tabular}

Fonte: Censos Agropecuários do Brasil.

Nota: * A área foi calculada em 31/12/95 e o número de árvores foi calculado em 31/07/ 96. O número de árvores inclui todas as espécies plantadas e os dados foram coletados no CD-ROM do Censo Agropecuário. Este valor é maior do que o que se encontra na versão impressa do Censo Agropecuário 95/96, pois este último não computou todas as espécies plantadas de árvores. 
Alguns aspectos devem ser destacados sobre a evolução do reflorestamento no Brasil, tais como:

- O acréscimo de área plantada entre 1975 e 2000 é cerca de 5\% do que foi desmatado apenas na Amazônia Legal entre 1975 e 1999.

- As florestas plantadas no Brasil plantam poucas espécies (como o eucalipto e o pinus) em sistema de plantio homogêneo, enquanto desmataram-se florestas heterogêneas. Por isso, as áreas plantadas não geram os mesmos benefícios ecológicos que foram perdidos com o desmatamento.

- A política de incentivos fiscais ao reflorestamento implicou altos custos em relação aos benefícios gerados. Bacha e Silva (1999), utilizando um modelo convencional de custo-benefício, concluíram que foram gastos recursos de US\$ 389,69 em incentivos fiscais para se gerar US\$ 1 de excedente econômico (a preços de dezembro de 1998). Isto se deveu, basicamente, aos altos custos do programa. No Brasil foram gastos US\$ $1.751,61$ de incentivos fiscais para cada hectare reflorestado. No Chile, um programa de incentivos fiscais gastou US\$ 77,78 por hectare reflorestado.

A redução do ritmo de reflorestamento nos últimos dez anos e a continuidade de expansão das indústrias de base florestal faz o Brasil se deparar com um novo dilema na primeira década do século 21: a falta de madeira de reflorestamento. ${ }^{12}$ Esta escassez afeta basicamente pequenas empresas (serrarias e indústrias de compensados) que não possuem recursos suficientes para o plantio de florestas, apesar desse plantio ser considerado lucrativo.

12 A escassez futura de madeira oriunda de reflorestamento no Brasil já havia sido alertada por BACHA (2001) e SBS (2000). Esta escassez já é assumida pelo Governo Federal. Na Síntese do Plano Agrícola e Pecuário 2002/2003, ao se referir ao Propflora - Programa de Plantio Comercial de Florestas, há o seguinte esclarecimento "O Brasil corre o risco de tornar-se, ainda nesta década, importador líquido de madeira. Objetivando atender a essa demanda e também os produtores que queiram recompor sua reserva legal, o governo está disponibilizando uma linha de crédito de $R \$ 60$ milhões para o plantio de florestas, principalmente para uso industrial ... ." (Síntese do Plano Agrícola e Pecuário 2002/2003, p. 4, disponível no endereço eletrônico http:// www.conab.gov.br). 
Os dados da Tabela 6 mostram que os plantios homogêneos com espécies florestais nativas (como araruva, pau-marfim e pinheiro brasileiro) e com espécies florestais exóticas (como eucalipto) apresentam taxa interna de retorno (TIR) igual ou superior ao plantio de outras culturas perenes (como laranjais e seringais). No entanto, o payback econômico dos plantios de eucaliptais é de 7 anos e de essências nativas atinge 25 anos. (ver Tabela 6).

TABELA 6 - ESTIMATIVAS DE ALGUNS INDICADORES DE RENTABILIDADE DE CULTURAS PERENES E FLORESTAIS NO ESTADO DE SÃO PAULO, CONSIDERANDO-SE A ANÁLISE DE RISCO E SEM INCLUIR O CUSTO DA TERRA

\begin{tabular}{lcc}
\hline Projeto & $\begin{array}{c}\text { Taxa interna de retorno } \\
\text { estimada }\end{array}$ & $\begin{array}{c}\text { Payback econômico } \\
\text { (número de anos) }\end{array}$ \\
\hline Pomar de laranjeira (em declínio) & 0,180 & \\
Pomar de laranjeira (sem declínio) & 0,192 & \\
Seringal (cenário otimista) & 0,196 & 25 \\
Seringal (cenário pessimista) & 0,144 & 25 \\
Araruva (com aquisição de mudas) & 0,169 & 25 \\
Araruva (com doação de mudas) & 0,222 & 25 \\
Pau-marfim (com aquisição de mudas) & 0,152 & 25 \\
Pau-marfim (com doação de mudas) & 0,192 & 25 \\
Pinheiro-brasileiro (com aquisição de mudas) & 0,170 & 7 \\
Pinheiro-brasileiro (com doação de mudas) & 0,197 & 7 \\
Eucalipto (com aquisição de mudas) & 0,254 & 0,298 \\
Eucalipto (com doação de mudas) & & \\
\hline
\end{tabular}

Fonte: MACHADO (2000) e NÉRIS (2001).

Esta situação de iminente falta de madeira de reflorestamento coloca a necessidade de se utilizar as florestas nativas de forma sustentável e/ou estimular o reflorestamento, caso se avalie como sendo importante a manutenção das atividades baseadas na madeira. 


\section{CONCLUSÃO E RECOMENDAÇÃO DE POLÍTICAS QUE LEVEM A UM NOVO PROCESSO DE DESENVOLVIMENTO COM USO SUS- TENTÁVEL DAS FLORESTAS}

De tudo o que foi exposto acima, pode-se confirmar a hipótese deste trabalho de que a destruição dos recursos florestais no Brasil e o uso insustentável do remanescente florestal sempre estiveram associados com as políticas desenvolvimentistas adotadas no País, as quais, por sua vez, se fundamentaram nos principais modelos econômicos em voga a cada período.

É certo que a preferência pelas políticas desenvolvimentistas adotadas ao longo do tempo se justifica pelos grupos de interesse que dominaram os órgãos formuladores de políticas econômicas.

Mas, como mudar esta situação?

A adoção de um novo modelo de desenvolvimento que dê maior atenção aos recursos florestais implica mudança de importância dos grupos de interesses nas formulações de políticas econômicas. Além disso, três conjuntos de alternativas, não excludentes, podem ser seguidas.

Uma primeira alternativa seria mudar os modelos econômicos que fundamentam as políticas macroeconômicas, priorizando aqueles que consideram o uso racional dos recursos naturais, como as florestas. Até o presente momento nenhum modelo macroeconômico de ampla aceitação foi desenvolvido de modo a incluir os recursos naturais entre as principais variáveis macroeconômicas (como produto, preços, taxa de juros, taxa de câmbio etc). No entanto, os modelos atuais podem ser reelaborados para colocar os recursos naturais como variável que restringe a oferta agregada.

A maioria dos modelos macroeconômicos de curva de oferta agregada parte do equilíbrio no mercado de trabalho, tomando uma função de produção onde os recursos naturais não são explicitados ou aparecem adicionados à variável capital, para a qual não há restrição de uso. Há divergências entre os modelos de curva de oferta quanto às formulações dadas ao mercado de trabalho e à função de produção. Por exemplo, os Modelos da Síntese Neoclássica consideram firmas e indivíduos maximizadores de lucros e renda-lazer, 
respectivamente, e uma função de produção com rendimentos marginais decrescentes do fator trabalho. (BRANSON \& LITVACK, 1978). Os Modelos dos Novo-keynesianos consideram que o salário é estabelecido com base no salário anterior e dependendo da taxa de desemprego da economia. A função de produção considera que os produtos médios do trabalho e dos insumos são constantes. (DORNBUSCH \& FISCHER, 1991).

Uma alternativa para considerar explicitamente os recursos naturais nestes modelos é incluí-los na função de produção ao lado dos fatores trabalho e capital. Além disso, pode-se considerar que o Produto Marginal e o Produto Médio dos recursos naturais são decrescentes, pois políticas de comando e controle limitam a sua exploração. Com isto, uma curva de oferta agregada que aumenta sua inclinação a cada ponto, até tornar-se vertical, surgirá.

A segunda alternativa seria enfocar o controle do desmatamento, não em termos de unidades produtivas (propriedades rurais), mas em termos de regiões. Neste sentido, o zoneamento ecológico-econômico (ZEE) seria uma alternativa, pois este pode definir as regiões segundo sua aptidão econômica e os benefícios ecológicos que a vegetação pode gerar. A partir desse zoneamento as políticas econômicas poderiam ser discriminatórias segundo as regiões definidas no ZEE.

É possível pensar em um zoneamento ecológico-econômico para todo o Brasil, identificando, no mínimo, três áreas: a livre para exploração, a que deve permanecer com recursos florestais para exploração sustentável e a que deve ser preservada. Para tanto, pode-se considerar as experiências e propostas atuais, procurando aprender sobre seus pontos positivos e fracos.

Há algumas propostas de ZEE para o Brasil, como o do Planafloro no Estado de Rondônia e de um sistema de florestas nacionais na Amazônia. (VERÍSSIMO et al., 2000). O Planafloro não apresenta resultados satisfatórios, em parte porque as políticas federais não o adotam. A proposta de Florestas Nacionais (Flonas) para a Amazônia Legal identifica 1,15 milhão de $\mathrm{km}^{2}$ na Amazônia Legal (correspondente a $23 \%$ do território desta região), que não são áreas protegidas e nem sujeitas a ação antrópica, mas que possuem alto potencial madeireiro. Essas áreas, se forem transformadas em florestas naci- 
onais, permitem gerar madeiras em sistema sustentável capaz de atender toda a demanda de toras da indústria madeireira situada na Amazônia Legal e possibilitar uma expansão de $60 \%$ na capacidade de produção desta indústria.

A terceira alternativa é a mudança de concepção e da valoração dos produtores e dos consumidores a respeito da importância dos recursos naturais, como as florestas. Isto já ocorre no caso de produtores que buscam a certificação ambiental e dos consumidores que privilegiam o consumo de produtos "ecologicamente corretos".

Alguns países europeus já são bastante suscetíveis ao consumo de produtos florestais que foram produzidos de maneira sustentável. Falta ampliar essa consciência para o mercado interno.

A procura pelo sistema de certificação é grande. O FSC-Brasil já tem certificado 286.675 hectares de florestas nativas.

O processo de certificação facilita a fiscalização da legislação florestal, pois a certificação avalia o cumprimento desta legislação.

\section{BIBLIOGRAFIA}

ALBUQUERQUE, M. C. C.; NICOL, R. Economia agricola - o setor primário e a evolução da economia brasileira. São Paulo: McGrawHill, 1987.

AZEREDO, N. R. S. O Brasil e o mercado mundial de produtos de madeira. Anais do $1^{0}$ Encontro Brasileiro de Economia Florestal, Curitiba, 23 a 27 de maio de 1988, p. 391 a 418.

BACHA, C. J. C. A evolução do desmatamento no Brasil. Revista de Economia e Sociologia Rural, Brasília, v. 34, n. 2, p. 111-135, nov./ dez. 1995.

. A dinámica do desmatamento e do reflorestamento no Brasil. 1993. Tese (Livre-Docência), ESALQ/USP, Piracicaba.

O Sistema agroindustrial da madeira no Brasil. Revista Econômica do Nordeste, Fortaleza, v. 32, n. 4, p. 975-993, out./dez. 2001. 
BACHA, C. J. C.; SILVA, M. M. P. Evolução do reflorestamento no Brasil impactos de políticas públicas e tendências. Relatório de pesquisa realizada com o apoio financeiro do Instituto Interamericano de Cooperação para a Agricultura (IICA). Piracicaba, abril de 1999, 59 páginas.

BACHA, C. J. C.; SHIKIDA, P. F. A. Experiências brasileiras na implementação do ICMS Ecológico. In: CASIMIRO FILHO, F.; SHIKIDA, P. F. A. Agronegócio e desenvolvimento regional. Toledo: Edunioeste, 1999, p. 179-207.

BASTOS FILHO, G. S. Contabilizando a erosão do solo: um ajuste ambiental para o produto bruto agropecuário brasileiro. 1995. Dissertação (Mestrado), ESALQ/USP, Piracicaba.

BAUMANN, Renato. O Brasil nos anos 1990: uma economia em transição. In: BAUMANN, R. (org.), Brasil - uma década em transição. Rio de Janeiro: Editora Campus, 2000, p. 11-53.

BLANCHARD, O. Macroeconomia - teoria e política econômica. 2a edição. Rio de Janeiro: Editora Campus, 2001.

BRANSON, W. H.; LITVACK, J. M. Macroeconomia. São Paulo: Editora Harper \& Row do Brasil Ltda, 1978.

BROWDER, J. O. Alternativas de desenvolvimento para florestas tropicais úmidas. In: LEONARD, H. J. (org.), Meio ambiente e pobreza estratégias de desenvolvimento para uma agenda comum. Rio de Janeiro: Jorge Zahar Editor, 1992, p. 126-149.

BUARQUE, C. Teoria econômica e meio ambiente. Revista do Serviço Público, v. 40, n. 4 , p. 83-92, out./dez. 1983.

CAMINO, Ronnie de. Sustainable management of natural forests: actors and policies. In: KEIPI, Kari (Editor), Forest resource policy in Latin America. Washington D.C.: Inter-American Development Bank, 1999, p. 93-109.

CARTERPILLAR. Manejo sustentável da floresta. Piracicaba: Manual e video, 1996.

CASTRO, C. M. Ecologia - a redescoberta da pólvora. Revista de Administração de Empresas, v. 15, n. 5, p. 6-19, set./out. 1975.

CIGNO, Alessandro. Growth with exhaustible resources and endogenous population. Review of Economics Studies, v. 48, n. 2, p. 281-287, abril de 1981.

COFO. The global forest resources assessement 2000 - summary report. Committee on Forestry, Food and Agriculture Organization. Rome, March 2001, 28 pages (disponível no endereço http:// www.fao.org). 
DALY, H. E. Toward a measure of sustainable social net national product. In: AHMAD, Y. J.; EL SERAFY, S.; LUTZ, E. (editors), Environment accounting for sustainable development. $3^{3}$ edição. Washington: The World Bank, 1992, p. 8-9.

DORNBUSCH, R.; FISCHER, S. Macroeconomia. 5a edição. São Paulo: Makron Books, 1991.

DOUROJEANNI, Marc J. The future of Latin America's natural forests. In: KEIPI, Kari (Editor), Forest resource policy in Latin America. Washington D.C.: Inter-American Development Bank, 1999, p. 7992.

EL SERAFY, S. The proper calculation of income from depletable natural resource. In: AHMAD, Y.J.; EL SERAFY, S.; LUTZ, E. (editors), Environment accounting for sustainable development. 3 a edição. Washington: The World Bank, 1992, p. 10-18.

FUNDAÇÃO SOS MATA ATLÂNTICA. Atlas da evolução dos remanescentes florestais e ecossistemas associados no domínio da mata atlântica no periodo 1990-1995. São Paulo: Fundação SOS Mata Atlântica, Instituto Nacional de Pesquisas Espaciais e Instituto Socioambiental, 1998, 38 páginas.

. Atlas dos remanescentes florestais da Mata Atlântica, periodo - 1995/ 2000. São Paulo: Fundação SOS Mata Atlântica e Instituto Nacional de Pesquisas Espaciais, 2002.

FURTADO, C. Formação econômica do Brasil. 23ª edição. São Paulo: Companhia Editora Nacional, 1989.

GOLDIN, I.; REZENDE, G. C. A agricultura brasileira na década de 80 crescimento numa economia em crise. Rio de Janeiro: IPEA, série IPEA, 138, 1993.

GILLIS, M.; REPETTO, R. Deforestation and government policy. International Center for Economic Growth, Cambridge University Press, 1988.

HARRINSON, A. Introducing natural capital into the SNA. In: AHMAD, Y. J.; EL SERAFY, S.; LUTZ, E. (editors), Environment accounting for sustainable development. $3^{\mathrm{a}}$ edição. Washington: The World Bank, 1992, p. 19-25

HUGON, P. História das doutrinas econômicas. 13ª edição. São Paulo: Editora Atlas, 1973.

INPE. Monitoramento da floresta amazônica brasileira por satélite 1999-2000. São José dos Campos: Instituto Nacional de Pesquisas Espaciais, maio de 2000. Disponível no site http://www.inpe.br.

IstoÉ. Natureza favorece o emprego. Revista IstoÉ, n. 1711, de 17/07/ 2002. 
MACHADO, J. A. R. A viabilidade econômica dos reflorestamentos com essências nativas brasileiras para a produção de toras - o caso do Estado de São Paulo. 2000. 186p. Dissertação (Mestrado), Escola Superior de Agricultura "Luiz de Queiroz", Universidade de São Paulo, Piracicaba.

MAHAR, D. J. Government policies and deforestation in Brazil's Amazon region. Washington, D.C.: The World Bank, 1989.

MOTTA, R. S.; YOUNG, C. E. F. Recursos naturais e contabilidade social: a renda sustentável da extração mineral no Brasil. In: Anais do $19^{\circ}$ Encontro Nacional de Economia. Curitiba, 3 a 6 de dezembro de 1991, V. 2, p. 235-252.

NÉRIS, C. N. Evolução e rentabilidade econômica do reflorestamento em pequenos e médios imóveis rurais - os casos de Minas Gerais, São Paulo e Paraná. 2001. 154p. Dissertação (Mestrado), Escola Superior de Agricultura "Luiz de Queiroz", Universidade de São Paulo, Piracicaba.

ROCHA, D. P. Evolução e sustentabilidade do setor industrial madeireiro no Estado de Rondonia. 1999. Dissertação (Mestrado), ESALQ/USP, Piracicaba, Brasil.

SACHS, Ignacy. Recursos, emprego e financiamento do desenvolvimento: produzir sem destruir - o caso do Brasil. Revista de Economia Politica, v. 10, n. 1, p. 111-132, jan.-mar. 1990.

SBS. Fórum de Competitividade da Cadeia Produtiva da Indústria de Madeira e Móveis - GT Madeira e Florestas. Documento apresentado em 10 de novembro de $2000.37 \mathrm{p}$.

SIMULA, Markku. Trade and environmental issues in forest production. In: KEIPI, Kari (Editor), Forest resource policy in Latin America. Washington D.C.: Inter-American Development Bank, 1999, p. 195-230.

STIGLITZ, J. E. Growth with exhaustible natural resources: the competitive economy. Review of Economic Studies (Symposium), p. 139-152, 1974.

STONE, S. W. Evolution of the Timber Industry along an aging frontier: the case of Paragominas (1990-95). World Development, v. 26, n. 3, p. 433-448, março de 1998.

VERÍSSIMO, A.; MATTOS, M.; BARRETO, P.; TARIFA, R.; UHL, C. Logging impacts and prospects for sustainable forest management in an old Amazonian frontier: the case of Paragominas. Forest Ecology and Management, v. 55, p. 169-199, 1992.

VERÍSSIMO, A.; SOUZA JÚNIOR, C.; AMARAL, P. H. Identificação de áreas com potencial para a criação de florestas nacionais na Amazônia 
legal. Brasília: Ministério do Meio Ambiente, setembro de 2000 (projeto UTF/BRA/047).

VIANA, V. M. As florestas brasileiras e os desafios do desenvolvimento sustentável: manejo, certificação e políticas públicas apropriadas. 2002. Tese (Livre-Docência), ESALQ/USP, Piracicaba.

ZANIOLO, A. Análise setorial das exportações brasileiras da indústria da madeira. Anais do $1^{\circ}$ Encontro Brasileiro de Economia Florestal, Curitiba, 23 a 27 de maio de 1988, p. 171-194.

ZENID, G. J. Identificação e grupamento das madeiras serradas empregadas na construção civil habitacional na cidade de São Paulo. 1997. Dissertação (Mestrado), Escola Superior de Agricultura "Luiz de Queiroz", USP, Piracicaba.

(Recebido em setembro de 2002. Aceito para publicação em janeiro de 2004). 